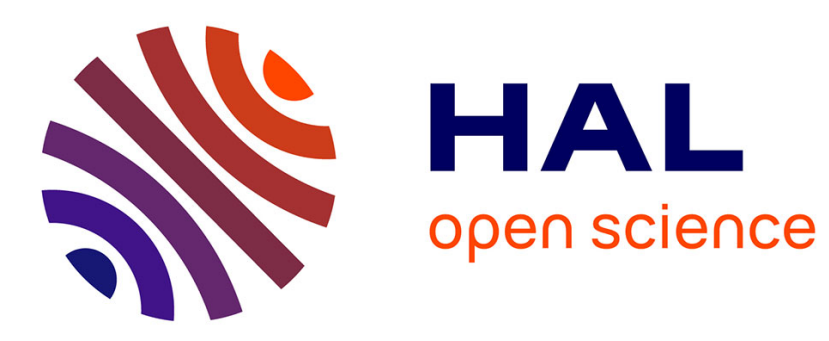

\title{
A Theoretical Approach to Energetic Materials
}

M. Cook

\section{- To cite this version:}

M. Cook. A Theoretical Approach to Energetic Materials. Journal de Physique IV Proceedings, 1995, 05 (C4), pp.C4-501-C4-503. 10.1051/jp4:1995440 . jpa-00253745

\section{HAL Id: jpa-00253745 https://hal.science/jpa-00253745}

Submitted on 1 Jan 1995

HAL is a multi-disciplinary open access archive for the deposit and dissemination of scientific research documents, whether they are published or not. The documents may come from teaching and research institutions in France or abroad, or from public or private research centers.
L'archive ouverte pluridisciplinaire HAL, est destinée au dépôt et à la diffusion de documents scientifiques de niveau recherche, publiés ou non, émanant des établissements d'enseignement et de recherche français ou étrangers, des laboratoires publics ou privés. 
JOURNAL DE PHYSIQUE IV

Colloque C4, supplément au Journal de Physique III, Volume 5, mai 1995

\title{
A Theoretical Approach to Energetic Materials
}

M.D. Cook

Defence Research Agency, Fort Halstead, Sevenoaks, Kent, U.K.

\begin{abstract}
This short paper reviews the current theoretical approach to understanding initiation and growth of reaction in energetic materials at Fort Halstead. Theoretical models at the molecular level are used to help develop algorithms at the macroscopic level which can then be used to model real systems.
\end{abstract}

The study of initiation and growth of reaction in energetic materials has been a rapidly expanding area of research over the last few years. At the microscopic level, many authors have produced decomposition schemes for a wide variety of explosives, but few have provided conclusive experimental evidence to back their predictions. Much of this is due to the great difficulty in experimentally studying fast reactions and identifying each individual step. Despite the difficulties, modern spectroscopic techniques are currently being successfully used to study decomposition reactions at the molecular level.

At the macroscopic level, there have been many many experiments carried out on a whole variety of explosive charges over the last century. However, these experiments have led to only rudimentary mathematical models which have limited application to predicting explosives behaviour.

On-the-other-hand the success of the ZND model at predicting the performance of ideal explosives is without question. However, new methodologies still need to be developed to obtain a better understanding and predictive capability particularly in the areas of initiation and growth of reaction, and to describe non-ideal behaviour.

At Fort Halstead we are developing a novel approach to help increase our understanding of the behaviour of explosives and develop predictive models based on well-founded physics and chemical principles. This is an entirely different approach to engineering fits that have been employed to-date. The whole approach is based on theoretical modelling of energetic materials at both the molecular and macroscopic levels.

At the molecular level, it is possible to model decomposition reactions using state-of-the-art Molecular Orbital (MO) codes. These codes have undergone a remarkable transformation within the last ten years or so and, together with ever increasing computing power, that is available at relatively low cost, provide a very powerful tool for investigating decomposition chemistry. MO codes will not replace 
experiment, but they can provide a valuable predictive capability which can help the experimentalist. Using such codes it is possible to obtain molecular geometries to within two percent of the experimental values; calculate thermodynamic data; calculate excited states; obtain a whole variety of spectral data; as well as calculate the energetics of reactions. The data obtained from such calculations can be used in other codes both microscopic and macroscopic. It should be noted that MO codes can only be used to perform calculations on at most a few molecules and more commonly only one or two at a time. When two or more molecules are involved in a calculation the whole system is treated as a 'supermolecule'.

Many more molecules can be included in calculations using either Monte Carlo or Molecular Dynamics methods. In these codes hundreds, if not, thousands of molecules can be treated within the model. However, the penalty for including more molecules in the calculation is that, in general, empirical potentials have to be used to describe the interactions between the molecules. However, it has been demonstrated, that it is possible to simulate the essential behaviour of a model explosive using an empirical potential which has an implicit 3-body term. Such models can be used very effectively to study the relationship between the chemistry and physics of explosives. Molecular dynamics calculations on model explosive systems show all the pertinent features that would be expected of real systems. For example, if in the simulation reaction is initiated by means of a flyer plate, then a critical velocity is required to obtain growth to detonation. A steady velocity of detonation is observed, and if the reaction is over-driven then the system still settles to the characteristic velocity of the model. The shock-wave that passes into unreacted material is followed by a zone of highly compressed material, which in turn is followed by the reaction zone, where most of the chemistry takes place. Finally, the reaction zone is succeeded by the gaseous products. This is what is generally observed in real solid explosives.

The gaseous products produced during the detonation are responsible for doing work on the external environment. For example, moving metal. It is important therefore to have a good description of their behaviour at elevated temperatures and pressures. Monte Carlo techniques can, and have been used to study the behaviour of the hot, dense gases in order to aid the development of new improved equations-of-state (EOS). It has been demonstrated using Monte Carlo calculations that many-body terms are required to describe the behaviour of the product gases. These EOS can then, in turn, be used in ideal detonation codes and hydrocodes to predict performance and macroscopic behaviour.

A major goal of any modelling effort must be to predict, from concept of a new energetic molecule its performance, compatibility, stability and sensitivity. Quantum chemistry codes can be used to generate intermolecular potentials which can be used in molecular dynamics codes and monte carlo codes. They can give good predicted geometries which can be used in crystal packing codes to obtain densities. They can also give thermodynamic parameters such as heat of formation. Density information together with heat of formation and an equation-of-state can be used in ideal detonation codes to give an idea of likely performance.

Potentials derived from MO codes can also be used in molecular dynamics simulations. Molecular dynamics simulations of explosives can, in principle, yield reaction kinetics. They can also give very useful physical property data. Both reaction kinetics and material property data can then in principle, be used in hydrocode models to predict sensitivity and other macroscopic properties.

The development of new algorithms to handle the ignition and growth of reaction in explosives is of fundamental importance. Incorporation of suitable routines into existing hydrocodes would allow a much improved predictive capability to model all-up weapon systems. The approach that has been taken at Fort Halstead is to develop an Arrhenius Burn Model that considers the growth of an explosive burn as a series of coupled kinetic steps. The rate of reaction of each step is a function of the concentrations of the constituents, the temperature and the pressure. Each reaction releases energy which fuels the burning process; if the release is sufficiently fast, the burn will run-away to detonation. The model is an attempt to consider the chemistry of the explosive realistically, rather than relying on cruder physical models involving arbitrary parameters. A particular feature of the model is that it employs temperature dependent Arrhenius kinetics. The model is currently being developed to handle both homogeneous and heterogeneous systems. For the latter, hotspots are explicitly considered in a separate routine but are nevertheless assumed to undergo decomposition via the same series of reaction steps. 


\section{Discussion}

\section{Kondrikov-Cook :}

$\mathbf{Q}$ : As a result of your calculations you have a critical velocity of a bullet, which can lead to detonation. If you compare the resuit with the experimental observations, you can precise the equation of state you use, and correspondingly the specific heat value and $(\mathrm{V}, \mathrm{T})$ dependence of it, which Dr. Gupta has spoken about.

Did you do this?

A : Our Arrhenius burn model uses an equation of state for both the products and the reactants. The reactant equation of state is a simple particle velocity shock velocity relationship. The products use the JHWL equation of state. The heat capacity $(\mathrm{Cv})$ used was the published value of the unreacted energetic material at room temperature. The Arrhenius kinetics are adjusted to fit the experimental data. The point that I raised in the presentation was that $\mathrm{Cv}$ is temperature dependent and that I had not included the temperature dependence in the calculations to-date. However, the temperature dependent behaviour of $\mathrm{Cv}$ can be calculated from stastistical thermodynamics and this will be used in the future. 